Revista Española de Antropología Americana

ISSN: 0556-6533

https://dx.doi.org/10.5209/reaa.77379

\title{
Tlacaxipehualiztli: la segunda fiesta en el Códice Tudela
}

\author{
María Isabel de la Rubia Rivas ${ }^{1}$
}

Recibido: 16 de julio de 2021 / Aceptado 31 de diciembre de 2021

Resumen. El presente artículo busca analizar el Libro Escrito Europeo y el Libro Indígena del folio $12 \mathrm{r}$ y 12v del Códice Tudela. El objetivo es resaltar la necesidad de atención de este manuscrito y recopilar y analizar su contenido. A través de esta información, estableceremos una comparativa para observar su originalidad en comparación con otros miembros de su grupo, acierto respecto a otras fuentes, características de sus pinturas y el orden de composición. No es objetivo de este estudio tratar aspectos propios de la religiosidad tradicional de los indígenas, sino concretar qué elementos buscaban destacar sus autores, y resaltar la importancia del análisis de los materiales para un estudio y aprovechamiento más productivo de su contenido.

Palabras clave: Códice Tudela; veintenas; Grupo Tudela; Grupo Magliabechiano; ritual.

\section{[en] Tlacaxipehualiztli: Second Festivity in Codex Tudela}

\begin{abstract}
This article seeks to analyze European Written and Indigenous Book on folio $12 \mathrm{r}$ and $12 \mathrm{v}$ of Codex Tudela. The objective is to highlight the need for attention to this manuscript and to compile and analyze its contents. Through that information, we will compare his originality in comparison with other members of his group, correction with respect to other sources, characteristics of his paintings and his order of composition. The objective of this study is not to deal with aspects of traditional religiosity of indigenous people, but to specify which elements their authors seeked highlight and to underline the importance of analyzing the materials for a more productive study and use of their content.

Keywords: Codex Tudela; twenty; Tudela’s Group; Magliabechiano's Group; ritual.
\end{abstract}

Sumario. 1. Introducción. 2. Primeras glosas y descripción del Libro Indígena. 3. Análisis del Libro Indígena. 4. Descripción del ritual en el Libro Escrito Europeo. 5. Conclusiones. 6. Referencias.

Cómo citar: Rubia Rivas, María Isabel de la. 2022. "Tlacaxipehualiztli: la segunda fiesta en el Códice Tudela”. Revista Española de Antropología Americana 52 (1): 45-58.

\section{Introducción}

A través de este artículo se busca destacar dos aspectos clave: la necesidad del análisis de las fuentes, concretamente del Códice Tudela, a la hora de considerarlo como tal; y el estudio de la información que sobre la fiesta de Tlacaxipehualiztli aportan tanto el amanuense que se ocupa del texto, como el tlacuilo que realizó previamente las pinturas (Batalla 2000). Antes de comenzar con el desglose y análisis de lo que

$1 \quad$ Universidad Rey Juan Carlos, Madrid. mi.delarubia@gmail.com 
este manuscrito contiene, se realiza un breve semblante del mismo, así como de las fuentes en las que nos centraremos para ello.

El Códice del Museo de América de Madrid o Códice Tudela debe su nombre a la institución donde se encuentra y a la persona que lo adquirió para el Museo en la década de los años 40 del siglo XX, José Tudela de Orden. Es un documento de difícil acceso, puesto que se guarda en la cámara del Museo de América de Madrid y sólo se puede consultar vía telemática a través de las imágenes de su página web (CERES s.f.). Precisamente por no poder consultarlo con facilidad, sus estudios son muy limitados, siendo los más importantes los de Elizabeth Boone (1983), sobre todo, los de Juan José Batalla (1993, 2001a, 2001b, 2002, 2008, 2009) y, más recientemente, los de Isabel de la Rubia $(2018,2021)$. A pesar de esta falta de atención, obras ya clásicas como las de Anders y Jansen (1993) y Anders, Jansen y otros (1991, 1993, 1994, 1996) emplean este documento para ilustrar algunas de las ideas que plantean otras fuentes. Dichos trabajos toman el Códice Tudela como prueba visual de sus afirmaciones, mientras que, de cara a mostrar referencias a su contenido, reparan en fuentes de mejor acceso, tales como el Códice Magliabechiano (Anders et al. 1996), lo cual aumenta la importancia del presente trabajo, el primero que se centra en el contenido partiendo de los trabajos que ya estudiaron el soporte (Boone 1983; Batalla 1999).

Como punto de partida, se tomará la teoría constatada, en nuestra opinión, por Batalla en sus trabajos $(2000,2008,2010)$, que señala la idea de que el Códice Tudela no es sino la cabeza del llamado grupo Magliabechiano. Aunque, también en nuestra opinión, ambas partes del Tudela están tan conectadas que sólo pueden perseguir un objetivo común. Para Batalla (2000) el Tudela fue constituido en dos fases, primero las imágenes, denominadas Libro Indígena, y después el contenido escrito en grafía occidental y lengua castellana, el Libro Escrito Europeo, y de esta confección derivaría la siguiente genealogía:

- De las pinturas del códice: Libro de Figuras, a mediados del siglo XVI, que contiene un comentario paralelo. De esta copia, redactada y pintada, derivarían tres más:

- La crónica de Cervantes de Salazar, que mezclaría textos del Tudela con los del Libro de Figuras.

- Las Viñetas de la Historia de Herrera.

- Códice Ritos y Costumbres, de la que surgirían:

- Códice Magliabechiano: considerado de manera tradicional cabeza del grupo hasta los estudios de Batalla (2000)

- Códice Ixtlilxochitl, del que derivaría:

- el Códice Veitia.

- Códice Fiestas, ya en el XVIII.

- Finalmente, del Libro Escrito Europeo: Códice Cabezón (Batalla 2008).

Basándonos en esto, se buscará demostrar que puede aportar más datos de los que contienen otros miembros de su grupo (Batalla 2000, 2008, 2010), pues, como se verá, el tlacuilo da gran cantidad de detalles que enriquecen elementos que no figuran en el Libro Escrito Europeo o que han podido perderse en copias posteriores, puesto que de facto, y según la genealogía aquí mostrada, el Códice Tudela presenta detalles únicos al aunar lo aportado por el amanuense y lo recogido por sus tlacuiloque. 
Por ello, en el presente artículo se desgranará la información del folio 12 del códice tomando como referencia obras contemporáneas al manuscrito (mediados del siglo XVI) como el Códice Florentino (1979) de fray Bernardino de Sahagún, la Historia de las Indias de Nueva España e Islas de Tierra Firme de fray Diego Durán, la Relación de la Provincia de Tezcoco de Pomar o la Descripción de la Ciudad y Provincia de Tlaxcala de Muñoz Camargo. Además, se recogerán los estudios realizados por relevantes autores (Caso 1967; Graulich 1982, 1999, 2000, 2005; Olivier 2010; Dehouve 2016, 2017; entre otros). Se analizará así sistemáticamente el folio 12 desde el marco donde se encuadra esta festividad en el Tudela, el Libro Escrito Europeo, las imágenes que se conservan en el folio 12r (Libro Indígena) y la descripción de la fiesta, mayoritariamente presente en el texto del folio $12 \mathrm{v}$.

\section{Primeras glosas y descripción del Libro Indígena}

La segunda fiesta del Xiuhpohualli, mal llamado calendario de 365 días (Díaz 2018), es la que el amanuense denomina tlacaxipeualiztli y que ocupará los folios $12 \mathrm{r}$ y $12 \mathrm{v}$ del manuscrito. La disposición de la información es similar al resto de la sección, esto es, una imagen y unas breves glosas que hacen referencia a cuestiones relativas al calendario cristiano con el que el amanuense pretende relacionar la fiesta:

tlacaxipeualiztli desollami(ento) de varon / \{a veynte de marco [tachado] $\}$ / $\{$ a dos de hebrero [tachado] / / a veynte y uno de hebrero / principal de mexico vestido con el cuero del esclabo muerto / el esclabo / principal de mexico

En este texto (Batalla 2009) se encuentran algunas correcciones que merece la pena destacar. La primera de ellas se debe a un intento de coherencia que tiene que ver con el inicio de las festividades, pues en la primera veintena, Xilomanaliztli, el autor también yerra y en ella se aprecia un tachón en las glosas, del mismo modo que en este caso (Rubia 2021). En el folio 11r se habla de "primero de febrero" y en nuestro caso "dos de febrero" y a continuación, "primero de marzo" en el folio 11r y "veinte de março" en el 12r. Aunque este detalle pueda parecer superfluo, da una pista sobre el orden de confección del códice más allá que el de los autores que nos precedieron (Boone 1983; Batalla 2000), que se limitaron a la cuestión de las secciones.

En este sentido la autora del presente artículo (2021) llega a la conclusión de que hubo varios periodos de confección dentro de esta sección del documento, debido al conjunto de correcciones en cuanto a las fechas y la diferencia en el número de las mismas, algunas corregidas hasta en tres ocasiones (Rubia 2021). Además de estos elementos, evidentes a simple vista, Batalla (2000: 202) pudo observar de primera mano el documento y mejorar la versión de Boone (1983), gracias a lo cual se sabe que en estas páginas hay dos tintas, lo que nos permite sostener esta idea de correcciones en varias fases ${ }^{2}$.

2 No se ha podido tener acceso al Códice Tudela por las medidas impuestas por el Museo de América para su estudio. Somos conocedores de la existencia de unos análisis llevados a cabo por la Universidad de Perugia en la década de los 2000, no obstante, no son accesibles aún hoy en día, por lo que tenemos que tomar los trabajos de Boone (1983) y Batalla (2000) al respecto. 
Con todo esto, respecto a la fecha que nos atañe, parece que se fijó en una segunda corrección, siendo la primera " 2 de febrero", que tacha y cambia por "veinte de março", para concluir dejando "a veyntiuno de febrero", circunstancia la de esta triple corrección que comparte con los folios ubicados entre el 14r y el 19r (Rubia 2021). Serán tales correcciones las que corroborarían a su vez las teorías de Boone (1983) y Batalla (2010) a falta de análisis químicos de las tintas.

Respecto al resto de la glosa, según los diccionarios consultados (Thouvenot y Manríquez 2014: 358), el término que emplea el amanuense sería tlaca (hombre) y Xipehualiztli (desolladura), en comunión con muchos de los códices que se manejan, como ya señalaba Alfonso Caso (1967, tabla X). No obstante, no es esta la única nomenclatura que existía según las fuentes, pues Graulich (1982: 217) afirma que también se llamaba Coahuitl, "fiesta de las serpientes". En este sentido, es importante esta omisión, por la relación de esta festividad con las serpientes de nubes y una supuesta vinculación de los sacrificados en ella con los cuatrocientos mimixcoa o serpientes de nube (Graulich 1999: 306).

Después del nombre de la festividad, se detallará el ritual en el texto que acompaña la parte inferior de la página, situando en medio el dibujo de la misma, el más detallado de cuantos rituales se describen en el Códice Tudela.

\section{Análisis del Libro Indígena}

Desde el punto de vista de las glosas, el amanuense señala tres figuras, dos de ellas como principales de México y la tercera, con la característica piedra atada, como esclavo. Atendiendo al Libro Indígena, se procede a continuación a describir los elementos que portan los personajes.

En primer lugar, la escena recuerda al estilo prehispánico (Batalla 2000: 138), pues no presenta similitud con imágenes de estilo occidental de otras secciones del Códice Tudela (2002: 1-4). Como se aprecia en el documento (CERES s.f.), el personaje de la parte superior va, según el amanuense, "vestido con el cuero del esclavo".

La escena consiste en un hombre ataviado con lo que parece la piel de un ser humano a modo de traje, con una franja a mitad del pecho identificable como la hendidura por la que se extraía el corazón y un collar de estos órganos al cuello similares a los que porta la imagen de la deidad del folio 46r (Códice Tudela 2002). En este sentido, a pesar de que el amanuense no señala explícitamente que porte en el cuello corazones, se encuentra una glosa señalando un elemento similar en el folio 51r del mismo documento (Códice Tudela 2002: 51r), lo que confirma el supuesto e indica que el amanuense conocía ese hecho, por lo que parece que la omisión se produce por un motivo diferente al desconocimiento. Asimismo, el personaje en cuestión está vestido con la piel de la víctima del sacrificio a la que previamente se le extraía el corazón (Graulich 2005: 118), de ahí que se da por hecho que se observa una escena relativa al ritual de esa fiesta. Si bien es cierto que no se puede afirmar que se trate de una única escena, sí parece evidente que es la deidad propia de la festividad (Díaz 2018), o el sacerdote que la encarna, como en otras páginas del manuscrito (Rubia 2021).

Respecto a esta primera figura, es conveniente señalar que desaparece en el Magliabechiano (1970: 30r) y que coincide con la descripción que hace Sahagún (1979, L.I, Cap. XVIII: 16r y v) del dios Xipe Totec, señor de esta festividad, que lo men- 
ciona como un hombre desnudo, con una tira estrecha en el lado de la cara, vestido de piel humana, orejeras de oro, sandalias y pendientes, así como una falda verde, un cetro y una rodela con un círculo rojo alrededor. Si se repara en esta descripción, podemos observar gran cantidad de elementos que coinciden con los que se encuentran en el Códice Tudela reproducidos por el tlacuilo, tales como la tira del rostro.

Estos aspectos, comunes a la representación de la deidad según otras fuentes, empiezan por dar una referencia de los conocimientos que sobre la divinidad y el ritual tenía el tlacuilo. No obstante, como se ha señalado, a pesar de esta buena caracterización, es más probable que se tratara de un sacerdote ataviado como la divinidad, tal y como dice el amanuense al llamarlo "principal del Mexico". Por otro lado, esta caracterización indica la trascendencia de sus atributos y su ambivalencia dependiendo de las funciones que les ocuparan y de la pluralidad de significados simbólicos, como señala Danièle Dehouve (2017: 22). Esta misma autora se refiere a que se establecería un vínculo entre aquellos que los portan, poniéndolo en relación con la "piel" o la "cobertura" y sosteniendo por tanto la idea de que "el personificador era vestido y envuelto en el traje representativo del dios personificado" (Dehouve 2016: 2). De este modo, que se vistan y se pinten como el mismo dios dejaría entrever, según Baudez (2010: 438), que "sin ellos [los vestidos y los atributos] los ritos no tendrían lugar o no serían eficaces", aunque eso no significa que el amanuense quiera representar una sola escena, sino probablemente la esencia de la festividad. Como se verá al referirse a las víctimas, estas también se identificaban con la propia divinidad (Graulich 1982; Dehouve 2016: 6), lo que debía saber el tlacuilo del Tudela, puesto que también otorga elementos del dios a la víctima que pinta. En este punto, se debe destacar que hay cierta combinación en la representación de las víctimas, pues si bien la que se encuentra en el Tudela aparece pintada de blanco, como las de la primera parte del ritual (Graulich 1999: 284), también figura con el ropaje y la caracterización de los sacrificados por sacrificio gladiatorio, lo que supone varias escenas en una sola.

En cuanto a la imagen que traslada el Códice Tudela, se trata de un hombre con la piel coloreada de rojo $^{3}$, una ropa que parece componerse de elementos blancos a modo de plumas, un sombrero que recordaría al del dios Xipe, rojo y blanco (Graulich 1999: 311) un arma, un escudo, cuyos círculos concéntricos representan el sol (Graulich 1999: 315) y una soga atada a la cintura que parece comunicarlo con una gran piedra. Por último, porta el mismo cetro que lleva aquel que encarna a la divinidad en el folio, lo que mostraría de nuevo la vinculación sacerdote-dios-víctima a la que se hacía referencia (Dehouve 2016: 9) y que se describe en las fuentes con el llamado "sacrificio gladiatorio".

Además, desde el punto de vista estético, el tercer personaje que se encuentra en la escena está representado también en los Primeros Memoriales (Sahagún s.f.: 250), donde se observa su sacrificio diferenciando tipos de víctima y la presencia de guerreros ataviados con pieles de jaguar y plumas de águila, algo que no se encuentra en este manuscrito.

Para concluir, es interesante resaltar de nuevo el conocimiento que parece poseer el tlacuilo pues, a pesar del hecho de que junte dos rituales, le da al personaje ata-

Una vez más se aprecia en esta imagen la escasa validez de lo contenido en el Magliabechiano (1970), dada la diferencia entre la calidad de las imágenes conservadas en el Tudela, en cuyo escudo se aprecian los detalles, y el Magliabechiano (1970: 29v), donde sólo se conserva el color. 
viado de jaguar la dimensión de guerrero Xipetotec (Dehouve 2017). Esta referencia se ve refrendada por la presencia de un elemento decorativo denominado aztaxelli o aztaxexelli que Vauzelle (2017: 89) recoge en su trabajo como un elemento bífido "compuesto de dos plumas de garceta blanca o sólo una divida en dos, y atada al pelo con una cinta roja llamada tochyacatl o tochacatl (FC, II: 114; VIII: 43)".

Como se puede observar a la luz de lo aquí expuesto, el tlacuilo parece poseer un amplio conocimiento sobre los rituales propios de esta festividad, lo que nos lleva a pensar que se trataba de un indígena (Batalla 2000; Rubia 2018), pero que, respondiendo al objetivo conjunto de la obra, debió respetar el espacio destinado a las pinturas y centrar la imagen, de tal forma que se percibiera lo más significativo del ritual, dado que el sacrificio de esclavos no era algo exclusivo de esta festividad, mientras que el sacrificio gladiatorio sí estaba reservado a ella.

\section{Descripción del ritual en el Libro Escrito Europeo}

En cuanto a la celebración del ritual, el amanuense lo recoge en una primera versión (folio 12r) y posteriormente lo amplia (folio 12v). En el recto dice:

[...] en este dia despues de muerto el esclabo el q(ue) le mataba despues de vestido su cuero del tomava la una mano del muerto y andaba pidiendo por el pu(ebl)o de [casa] en casa y por las ferias e mercados e todos le davan de [lo que] tenian duraba esta fiesta veynte dias y cada dia ponia [la mano] del muerto sobre su casa [para que la viesen y por ella conociesen aver el hecho el cativo] ${ }^{4}$

En primer lugar, el autor del Tudela se limita a señalar un solo ritual frente a los dos que recogería Sahagún en la víspera del último día, un sacrificio de esclavos que morían desollados (Sahagún 1979, L. II, Cap. XX: 18r), y al final de la veintena el sacrificio gladiatorio (Sahagún 1979, L.II, Cap. XX: 19r). Así, la pintura que se observa en la parte superior del folio 12 r, donde se ve un individuo ataviado con la piel de otro ser humano, es sin duda una referencia a la deidad y al ritual que describe Sahagún (1979, L.I, Cap. XVIII: 16v), pero en el verso, se describirá la segunda parte del rito que se aprecia en las imágenes.

En este sentido, una hipótesis que se podría formular, dado el conocimiento que parece demostrar el tlacuilo y la aparente exactitud de los personajes retratados, es que cada una de las tres figuras recogidas en el recto del folio, hiciera referencia a una parte del ritual. Si bien es cierto que podría plantearse por la presencia de esclavos en ambas descripciones de Sahagún, el hecho de que el individuo de blanco porte macana, una soga y esté atado a una piedra, parece ponerlo en relación con el guerrero frente al que se encuentra. No obstante, la figura de la deidad sí puede ser entendida como una referencia a la festividad, y no necesariamente como parte de la escena.

Respecto al contenido del texto, el Tudela, igual que Durán (1923, L. II, Cap. III: 271) habla de que iban de casa en casa ataviados con la piel de los difuntos pidiendo limosna. Este factor de la mendicidad es relevante para la genealogía del

Este tipo de referencias, entre corchetes y en cursiva, pertenecen a la información que se ha perdido en el original y se conserva en el Códice Cabezón (Batalla 2009: 91). 
códice, pues sólo se encuentra presente en el Códice Cabezón (Gómez de Orozco 1945), copia muy tardía del Tudela (Batalla 2000, 2009) y, como se ve, en la obra de Durán, hecho que invita a poner en relación ambas fuentes. Respecto al uso de la piel, Graulich (1999: 288) señala que servía para detectar el advenimiento de un año fértil en función de si sudaba o no, recibiendo regalos en caso afirmativo. Quizá, dada la "traducción" cultural que realizan los autores del Tudela para poder explicar comportamientos diferentes a los cristianos, fuera la mendicidad la explicación más plausible para un profano en la cultura.

Respecto a la idea de la mano cortada que otorgaría fuerza vital al que la portara, en el Libro Indígena no aparece nada, aunque no se puede dejar de señalar la presencia del dios Tezcatlipoca en el Códice Borgia (Anders, Maarten y Reyes 1993: 11), lo que algunos han querido ver como la posesión de "poderes mánticos espantosos" (Anders, Maarten y Reyes 1993: 100). Por otro lado, en el resto de fuentes no se encuentra referencia alguna, más allá de la idea que nos transmite Sahagún (1979, L.II, Cap. XXII: 25v) sobre el uso de huesos de sacrificados aderezados con papel en los patios durante esta veintena, lo que puede estar vinculado a la fuerza vital (González 1985: 281).

Continuando con la lectura del documento (fol. 12v) el amanuense dice (Batalla 2009: 92-93):

[...] la fiesta de atras es que a veynte de março se celebraba desta manera de los yndios cativos en la guerra de tascala o mechuacan o yopetzinco si catibavan algun señor o capitan le tenian \{con [interlineado]\} guardas y a recado hasta este dia en el qu(a)l un capitan de mex(i)co yba a motencuma o al señor q(ue) governaba y le hablaba poniendole por delante los servicios q(ue) le avia hecho y deseava hazer y le suplicaba le diese licencia para pelear con un esclavo y el se(ño)r se la dava y no era pequeña $\mathrm{m}(\mathrm{er}) \mathrm{c}(\mathrm{e}) \mathrm{d}$ q(ue) le hazia y tomavan al esclabo o catibo capitan y dabanle las armas de q(ue)l se armaba y acostumbrava traer en la guerra y atavanle una soga de cinco braças al cuerpo y el otro cabo ataban a una piedra redonda con un agujero por medio y esta piedra oy en dia esta en la placa de mex(i)co junto al acequia del agua cabe las casas del marq(ue)s y ansi atado y armado aguardaba al q(ue) abia de pelear con el el qu(a)l venia armado con un cuero de tigre o leon o otras armas como cada uno queria y peleavan y muerto el esclabo q(ue) siempre morian por estar atados [letras tachadas] desollabanle el cuero y vestiasele el vencedor y sacavanle el coracon y echabasele al cuello y llebavanle todos los señores con gran mitote y fies $[\mathrm{ta}]$ antel diablo y alli baylaban tres dias y avia borrach[era] y sacrificios de copal y papel y si por caso algun esclavo mataba al s(eñ)or de mex(i)co que peleaba con el hacia lo mesmo y le llebaban ante el s(eñ)or el qu(a) 1 le elejia por su capitan en una frontera lexos de su tierra porq(ue) no se le alcase $[\ldots]$

En este texto es difícil establecer una separación por temas, de ahí que se haya optado por no dividir el fragmento. Lo primero es la cantidad de datos que aporta el amanuense, desde la procedencia de los sacrificados hasta la custodia, los permisos o el proceso de la ejecución. Además, fija este texto a la vez que la segunda de las versiones de las fechas. Ello se demuestra si se atiende a que no modifica, como en el resto del folio, el "veynte de março" como momento de la ejecución, que no se corresponde con la fecha inicial ni con la final, lo que lleva a dos conclusiones: la 
primera, que el folio fue escrito en el recto y en el verso a la vez y que sólo fue modificado el primero; y la segunda, que el amanuense limita definitivamente la fiesta a un solo día y no a varios, como en el caso de la obra de Sahagún.

En cualquier caso, muestra una información muy concreta acerca del ritual ya que, además de la fecha, dice que los prisioneros escogidos para este tipo de sacrificio eran capitanes o miembros concretos de fuerzas procedentes de Tlascala, Michuacan o Yopetzinco y que se les guardaba bajo custodia. Aunque referido a prisioneros de la Huasteca, Durán también cita un gran sacrificio gladiatorio con la presencia de grandes mandatarios de zonas próximas a Tenochtitlan (Durán 1995, I, L. I, Cap. XX: 226).

La procedencia de las víctimas también debe llamar la atención, en tanto en cuanto no serían escogidas aleatoriamente, sino guerreros, por la vinculación ritual de este sacrificio con la guerra (Bueno 2009: 186); por otro lado, procederían de los lugares señalados por Durán como participantes de las guerras floridas (Durán 1995, I, L.I, Cap. XXI: 289), conflictos que se dirigían a la obtención de víctimas honrosas para el sacrificio (Alicino 2019).

Respecto a aquellos a los que se enfrentaban, dice que pertenecían también a la élite de las fuerzas mexicas y que el choque era considerado un honor, pues "no era pequeña la merced". De hecho, según Pomar (1891: 18), eran escogidos por el propio rey habiendo obtenido previamente referencias de su valía, lo que confirma la información del Tudela y permite relacionar este rito con las guerras floridas, con la necesidad de víctimas y con el componente político del sacrificio humano (Bueno 2009: 189).

Continuando con la lectura, se debe señalar que el amanuense describe las armas de la futura víctima y del guerrero sin hacer distinción, algo que se ve a simple vista en la imagen, y puntualiza que el primero debía llevar atada a la cintura una soga de cinco codos que le unía a una gran piedra, con lo que enriquece el detalle que nos aporta el pintor dándonos la medida concreta (dos metros aproximadamente) (Romero 2004: 67) e incluso dónde se encontraba, pues se refiere a la casa de Cortés.

En cualquier caso, ambos detalles son llamativos. Si se refiere a la indumentaria que portaban los guerreros, no es la única fuente que habla de que vestían con pieles de animales. En el Tudela se habla de leones, Sahagún (1979, L.II, Cap. XXI: 19r) se refiere a tigres, en cualquier caso, dado el tipo de felinos de los que proliferan en Mesoamérica, se opta generalmente por el término "jaguar".

En cualquier caso, un detalle que no se encuentra en esta fuente, es la idea del "rayamiento" que Graulich (1999: 289) ve presente en las garras del personaje representado en el Códice Nutall y en la afirmación de Sahagún (1979, L.II, Cap. XXI: 21v) y que lleva también el guerrero del Tudela, aunque según el amanuense no tengan uso en este caso.

Así mismo, es evidente que, aunque se haya mencionado la relación de rito con Xipe y se vean otras referencias, lo que Sahagún (1979, L.II, Cap. XXI: 21v) menciona sobre el rayamiento no aparece en el Libro Escrito Europeo del Códice Tudela, pero sí en la imagen del Libro Indígena a pesar de que el mismo amanuense realiza cambios en otros puntos del documento (Boone 1983; Batalla 2001a; Rubia 2018). Precisamente si se atiende a la imagen, se debe señalar el gran detalle del tlacuilo, a veces excesivo como en el caso de la macana del esclavo, que porta obsidianas y bolas de algodón, pero que relaciona el Tudela con otras fuentes como el Códice Florentino y lo distancia del Códice Magliabechiano por la ausencia de los mismos en este, si exceptuamos los círculos presentes en la roca. 
Respecto a su ubicación, es interesante el hecho de que se señale exactamente, dado que la piedra empleada para el sacrificio gladiatorio ha sido buscada en las inmediaciones de la actual plaza del Zócalo desde que fue insinuada su existencia por Brantz Mayer en 1841, hasta las recientes excavaciones del Templo Mayor (Matos Moctezuma y López Luján 2012). En cualquier caso, el amanuense del Tudela la menciona e insinúa su lugar, algo que podría invitar a pensar en la llamada "Piedra Pintada", que se encontraba en el contexto de la Plaza Mayor de México, ocupada antes de la Conquista por el recinto del Templo Mayor (Matos Moctezuma 2012) y concretamente en una plaza diáfana colindante a una acequia.

Continuando con la lectura, el amanuense afirma que una vez se producía el enfrentamiento, se desollaba al esclavo muerto y vestía su piel aquel que lo había vencido. A continuación, se le sacaba el corazón y se ponía en el cuello, algo que no recogen otras fuentes, que sí señalan lo que hacían con el corazón de las víctimas, poniendo el órgano ofrecido en una jícara y ofreciendo la sangre al dios con una caña (Sahagún 1979, L.II, Cap. XXI: 22r).

En este punto, es interesante resaltar que la imagen descrita por el amanuense es la que se corresponde con la figura de la parte superior del folio $12 \mathrm{r}$, lo cual puede servir de referencia, como ya se ha mencionado, bien del dios del ritual, bien a esta parte del mismo, lo que pone en relación tanto al Libro Indígena con el Libro Escrito Europeo, como a estos con otras fuentes.

Por otro lado, no es la única ocasión en la que se ve el empleo de los corazones como ofrenda a los dioses, lo que pone en relación esta sección con otras del mismo documento (Códice Tudela 2002, fol. 51r, 53r y 46r) y permite hablar de una coherencia interna de la que el amanuense era consciente, tal y como se recoge en otros folios del manuscrito.

Además de esta ofrenda, el amanuense se refiere también al uso de copal y papel, algo que de nuevo se ve en otros folios del Tudela (2002: 13r, 15r, 21v, 22r, 25r, 26r, 28r, 50r y v, 84r, 91r, 92r y v, 93r y v y 96 r y v) y que parecen ser más bien un elemento común al conjunto de los rituales o, cuanto menos, un recurso recurrente en lo que al amanuense se refiere. En este sentido, se debe destacar que no se hace referencia al consumo de carne ritual por aquellos que hacían la ofrenda, algo que se encuentra en otras fuentes (Sahagún 1979, L. II, Cap. XXI: 18v) y que no deja de llamar la atención, aún más si se tiene en cuenta que aparece como tal en otra sección del Códice Tudela (2002: 64r), lo que lleva a pensar en una omisión intencionada, evitando la senda de la crítica severa de autores como Durán (1923, II: 250)

En lo que respecta a la referencia a la celebración de la fiesta y la supuesta borrachera, es de señalar que según Graulich (1999: 304), a los propios cautivos también se les daba una buena cantidad de pulque y que Sahagún cuenta que las fiestas, los bailes y los convites se extendían a lo largo de toda la veintena (Sahagún 1979, L. II, Cap. XXI: 23r).

Respecto al destino de los esclavos que iban al sacrificio, el amanuense es claro y afirma que morían todos, no obstante, deja entrever que en alguna ocasión se les perdonaba la vida, como cuando dice que a aquellos que sobrevivían se les hacía capitanes de las fronteras, eso sí, alejadas de su territorio, lo que supone una contradicción. Lo que sí se puede constatar es que este hecho aparece en fuentes como la crónica de Muñoz Camargo, quien habla de un tal Tlahuicole que, según la fuente, era otomí o tlaxcalateco (Bueno 2009: 197) y que no sólo sobrevivió a la captura, sino que hasta capitaneó a las tropas mexicas a la victoria frente a los tarascos de Michoacán, tras lo 
cual, renunció solicitando el sacrificio por ser más honroso (Muñoz Camargo 2007, Cap. XV: 125-128). Aunque esto invita a pensar que el autor era conocedor de esta leyenda, este hecho se considera algo sumamente improbable, pues Graulich (2000) ve en las incoherencias de las diversas versiones, un intento de legitimación.

Al margen de esto, lo importante acerca de esta fiesta es el hecho de que se limite a la celebración del sacrificio gladiatorio, sin terminar de referenciar las prácticas ni el destino que se les daba a los caídos en el mismo, aparte de indicar someramente que se vestían con el cuero del difunto. Ni la reutilización de las pieles que señalan Sahagún (1979, L. II, Cap. XXI) o Durán (1923, II, L. II: 271), ni el consumo de carne humana que se aprecia en esas mismas fuentes, e incluso en otras páginas del Códice Tudela, es señalado aquí, por lo que se da por finalizado el ritual con la fórmula fija que emplea el amanuense, una difusa referencia a bailes, areitos, borracheras y ofrendas de papel y copal que, por otro lado, sólo se ha encontrado en Durán (1923, II, L. II: 272).

\section{Conclusiones}

La idea de la que se partía en origen era que el contenido del Códice Tudela se ha demostrado interesante a nivel codicológico (Boone 1983; Batalla 1999), pero no se puede obviar tampoco el valor de su contenido. El hecho de que el amanuense deje de lado informaciones que contienen otras crónicas, nos indica que, o bien no le interesaban o bien las desconocía, puesto que no las nombra ni tan siquiera brevemente, aunque sea conocedor de algunas de ellas, puesto que aparecen en otras secciones del códice.

Lo aquí recogido se traduce, además, en que hay dos factores de análisis en la obra, puesto que se aprecian contenidos en ocasiones distintos, pero siempre complementarios, como los pertenecientes al Libro Indígena y el propio del Libro Escrito Europeo, y que el primero parece más rico en detalles y en consonancia con otras fuentes que el segundo. Esta idea de la doble lectura ya fue formulada en su día por Batalla (2000) y se ha demostrado vital en el presente análisis por la mencionada complementariedad de la información. Con esto, lo que se puede concluir en primer lugar, después del análisis de estos dos folios del manuscrito, es que hay un trabajo continuado de elaboración y revisión en el documento que no está privado de errores y correcciones.

El más evidente de estos fallos se contempla en la cuestión de la temporalización de los periodos. Aquí no se puede dejar de destacar que, aunque existe una modificación de la fecha en el recto del folio, no la hay en el verso, lo que permite afirmar que el texto, que no las glosas, fue escrito de una vez, pero no revisado, de ahí que sí se corrija en el recto, donde es más visible el error, pero no en el verso. Esto afirmaría la idea del orden de confección de la sección que ya planteaba la autora de este artículo recientemente (2021).

En segundo lugar, se aprecia la divergencia de conocimientos o de fuentes de ambos libros. Si bien el Libro Indígena es rico en detalles, como se ha podido ver en lo detallado de la escena del folio 12r, empezando por la presencia de un personaje más, el amanuense limita de forma muy clara el contenido, lo corrige y no lo amplía. Esto llama la atención porque sí lo hace en el caso del Tonalpohualli (Batalla 2000; Rubia 2018), dejando algunos elementos propios de esta fiesta recurrentes en las crónicas, tales como el canibalismo ritual, sin mencionar. 
Este hecho solo podría ser explicado bien por el desconocimiento, lo que parece improbable por la presencia de estos rituales en otras páginas y por el conocimiento que parece demostrar, o bien por omisión voluntaria, por lo que nos inclinamos (Rubia 2018). En cualquier caso, aunque el amanuense omitiera detalles voluntaria o involuntariamente, algo que no podemos determinar, el tlacuilo sí legó imágenes con un gran detalle, lo que reafirma la trascendencia del documento.

Respecto a la lectura de las imágenes del manuscrito, se señalaría la idea de una doble lectura. Por un lado, la imagen puede interpretarse como un ritual, el sacrificio gladiatorio representado en la parte inferior, bajo la supervisión de la imagen de una divinidad claramente caracterizada; y por otro, la idea de que dos rituales diferentes, el sacrificio gladiatorio por un lado y la mendicidad de los ataviados con las pieles por otro. Además, la divinidad representada trae de nuevo la idea de la gran ambivalencia sacerdote-dios-víctima que tanto han destacado otros autores (Dehouve 2016: 9).

Continuando con el contenido, se debe resaltar la originalidad de las informaciones que aporta, tales como la presencia de la ubicación de la piedra en un espacio concreto de la Ciudad de México, la mendicidad de los sacerdotes, la idea de la mano cortada que se ve en otras fuentes, pero no en el mismo contexto y que aún estamos en proceso de interpretar, entre otros.

En este sentido, creemos interesante reparar en los detalles que comparte con la obra de Durán, como la referencia a la procedencia de los guerreros o su relación, en este caso no explícita, con las guerras floridas o el peregrinaje de los sacerdotes vestidos con la piel de los sacrificados. Este hecho nos pone de nuevo sobre aviso de la relación existente entre las fuentes, aunque el objetivo del amanuense del Tudela parece ser más informativo y menos crítico que el de Durán.

Así mismo, la diversidad de uno y otro libro en el seno del mismo códice hace reafirmarse en la idea de que este folio, cuanto menos, tiene dos autores: uno responsable de Libro Indígena y probablemente indígena y otro, el amanuense, con toda probabilidad occidental. En cualquier caso, algo que no se debe pasar por alto, es que ambas manos presentaban el objetivo común de confeccionar una obra coherente y cohesionada como la que se encuentra.

Para concluir, a la luz de lo aquí recogido se puede asegurar que documentos como el que nos ocupa, que apenas han recibido atención, una vez estudiados desde el punto de vista de su soporte como han hecho los estudios que nos precedieron, constituyen una fuente original e interesante para profundizar no sólo en el conocimiento de la religión indígena del Centro de México, sino para determinar la propia originalidad de la información que contienen; su relación con otras fuentes y el ejercicio de transculturación que supuso la comprensión de los conquistadores de una cultura entonces casi desconocida y aún no completamente descifrada.

\section{Referencias}

Alicino, Laura, 2019. "El concepto de xochiyaoyotl en el mundo prehispánico según las Relaciones de Chimalpáhin Cuauhtlehuanitzin”. Ancient Mesoamerica 30 (2): 235-244.

Anders, Ferdinand y Maarten Jansen. 1993. Códice Vaticano B. Manual del adivino. México: Sociedad Estatal Quinto Centenario, Akademische Druck-und Verlagsanstalt, Fondo de Cultura Económica. 
Anders, Ferdinand, Maarten Jansen y Gavina A. Pérez Jiménez. 1994. Códice FejérváryMayer. El libro de Tezcatlipoca, señor del tiempo. México: Akademische Druck-und Verlagsanstalt, Fondo de Cultura Económica.

Anders, Ferdinand, Maarten Jansen y Luis Reyes García. 1991. Códice Borbónico. El libro del Ciuacóatl: Homenaje para el año del Fuego Nuevo. México: Sociedad Estatal Quinto Centenario, Akademische Druck-und Verlagsanstalt, Fondo de Cultura Económica.

- 1993. Códice Borgia. Los templos del cielo y de la oscuridad, oráculos y liturgia. México: Sociedad Estatal Quinto Centenario, Akademische Druck-und Verlagsanstalt, Fondo de Cultura Económica.

Anders, Ferdinand, Maarten Jansen y Alejandra Cruz Ortiz. 1994. Códice Laud. Pintura de la muerte y los destinos. México: Akademische Druck-und Verlagsanstalt, Fondo de Cultura Económica.

Anders, Ferdinand, Maarten Jansen, Jessica Davilar y Anuschka Van’t Hooft. 1996. Libro de la vida. Texto explicativo del llamado Códice Magliabechiano. México: Akademische Druck-und Verlagsanstalt, Fondo de Cultura Económica.

Batalla Rosado, Juan José. 1993. "El Códice Tudela: análisis histórico y formal de su primera sección". Anales del Museo de América 1: 121-142.

—. 1999. "Estudio codicológico del Códice Tudela". Anales del Museo de América 7: 7-63.

-. 2000. El Códice Tudela o Códice del Museo de América. Tesis de Doctorado. Universidad Complutense de Madrid. El Códice Tudela o Códice del Museo de América y el Grupo Magliabechiano - E-Prints Complutense (ucm.es).

—. 2001a. "Tintas utilizadas por el amanuense del Libro Escrito Europeo del Códice Tudela". Anales del Museo de América 9: 219-253.

—. 2001b. "Nuevas hipótesis sobre la historia del Códice Tudela o Códice del Museo de América". Anales del Museo de América, (31):131-164.

—. 2002. "El número de tlacuiloque-"pintores" del Libro Indígena del Códice Tudela". Revista Española de Antropología Americana 32: 127-177.

—. 2008. "El libro escrito europeo del códice fiestas de los indios a el demonio en días determinados y a los finados". Itinerarios 7: 9-46.

—. 2009. "El Libro Escrito Europeo del Códice Tudela o Códice del Museo de América, Madrid". Itinerarios 9: 83-115.

—. 2010. "La importancia del Códice Tudela y la escasa validez del Códice Magliabechiano para el estudio de la religión azteca: el mal llamado Grupo Magliabechiano". Anales del Museo de América 18: 7-27.

Baudez, Claude-François. 2010. "Sacrificio de "sí", sacrificio del "otro", en El sacrificio humano en la tradición religiosa mesoamericana, Leonardo López Luján y Guilhem Olivier, eds., pp. 431-451. México: Instituto Nacional de Antropología e Historia, Instituto de Investigaciones Históricas, UNAM.

Boone, Elizabeth H. 1983. The Codex Magliabechiano and the Lost Prototype of the Magliabechiano Group. Berkeley y Los Ángeles: University of California Press.

Bueno Bravo, Isabel. 2009. "El sacrificio gladiatorio y su vinculación con la guerra en la sociedad mexicana". Gladius 29: 185-204.

Caso, Alfonso. 1967. Los calendarios prehispánicos. México: Instituto de Investigaciones Históricas, UNAM.

CERES. Colecciones en Red. Red Digital de Colecciones de Museos de España. http://ceres.mcu.es/pages $/$ Viewer?accion $=4 \& M u s e o=\& A M u s e o=M A M \& N i n v=70400 \&$ txt_id imagen $=8 \&$ txt_rotar $=0 \&$ txt_contraste $=0$. 
Códice Florentino. 1979. Edición facsímil en 3 volúmenes del original conservado en la Biblioteca Medicea Laurenziana de Florencia. México: Secretaría de la Gobernación.

Códice Magliabechiano. 1970. Edición facsímil. Einleitung Summary und Resumen Ferdinand Anders. Graz: Akademische Druck-und Verlagsanstalt.

Códice Tudela. 2002. Edición facsímil. Volumen de estudio de Juan José Batalla Rosado. Torrejón de Ardoz: Ministerio de Educación, Cultura y Deportes, Agencia Española de Cooperación Internacional, Testimonio Compañía Editorial.

Dehouve, Danièle. 2016. "El papel de la vestimenta en los rituales mexicas de "personificación". Nuevo Mundo, Mundos Nuevos. Coloquios. https://doi.org/10.4000/nuevomundo.69305.

—. 2017. "Los nombres de los dioses mexicas. Hacia una interpretación pragmática". Trace 71: 9-39. http://dx.doi.org/10.22134/trace.71.2017.27.

Díaz Álvarez, Ana. 2018. "Nombrar las veintenas en los códices. Estrategias coloniales de reconfiguración gráfica del año entre los nahuas". Anales del Instituto de Investigaciones Estéticas XL (113): 145-195. https://doi.org/10.22201/iie.18703062e.2018.113.2653.

Durán, Diego. 1923. Historia de las Indias de Nueva España e Islas de Tierra Firme, Publ. [By] J.F. Ramirez [with] Explicación del códice Jeroglifico de Mr. Aubin. Por A. Chavero. 2 Tom. [And] Atlas. Edición Facsímil. México: Nabu Public Domain Reprints.

- 1995. Historia de las Indias de Nueva España e Islas de Tierra Firme. México: Consejo Nacional para la Cultura y las Artes.

Gómez de Orozco, Federico. 1945. Costumbres, fiestas y enterramientos y diversas formas de proceder de los indios de Nueva España. Tlalocan 2 (1): 37-64.

González, Yolotl. 1985. El sacrificio humano entre los mexica. México: Fondo de Cultura Económica.

Graulich, Michel. 1982. "Tlacaxipehualiztli ou la féte aztéque de la moisson et de la guerre". Revista Española de Antropología Americana 12: 215-254.

- 1999. Fiestas de los pueblos indígenas. Ritos aztecas. Las fiestas de las veintenas. México: Instituto Nacional Indigenista.

—. 2000. "Tlahuicole, un héroe tlaxcalteca controvertido", en El héroe entre el mito y la historia, Federico Navarrete y Guilhem Olivier, coords., pp. 89-100. Instituto de Investigaciones Históricas, UNAM, Centro de Estudios Mexicanos y Centroamericanos.

—. 2005. Le sacrifice humain chez les Aztèques. Paris: Fayard.

Matos Moctezuma, Eduardo. 2012. "La Plaza Mayor o Zócalo en tiempos de Tenochtitan". Arqueología Mexicana 116: 24-27.

Matos Moctezuma, Eduardo y Leonardo López Luján. 2012. "El insólito caso de la 'piedra pintada". Arqueología Mexicana 116: 28-35.

Muñoz Camargo, Diego. 2007. Historia de Tlaxcalla. Alicante: Biblioteca Virtual Miguel de Cervantes. http://www.cervantesvirtual.com/obra-visor/historia-de-tlaxcala--0/ html/1b8b1 fa4-b981-4eff-8e8e-29bba72dbdc8_41.html.

Olivier, Guilhem. 2010. "El simbolismo sacrificial de los Mimixcoa: cacería, guerra, sacrificio e identidad entre los mexicas" en El sacrificio humano en la tradición religiosa mesoamericana, Leonardo López Luján y Guilhem Olivier, eds., pp. 453-481. México: Instituto Nacional de Antropología e Historia, Instituto de Investigaciones Históricas, UNAM.

Pomar, Juan Bautista. 1891. Relación de Texcoco. México: Imprenta de Francisco Díaz de León.

Romero García, Rafael Eugenio. 2004. "Medidas antiguas españolas". Técnica industrial 254: 64-67. https://www.tecnicaindustrial.es/wp-content/uploads/Numeros/13/43/a43.pdf. 
Rubia Rivas, María Isabel de la. 2018. Análisis integral del Tonalpohualli del Códice Tudela o Códice del Museo de América de Madrid. Tesis de doctorado. Universidad Complutense de Madrid

—. 2021. "Xilomanaliztli: la primera fiesta de las veintenas en el Códice Tudela". Itinerarios 34: 91-113.

Sahagún, Fray Bernardino de. s.f. Primeros Memoriales. Códices Matritenses de la Real Biblioteca. http://bdmx.mx/documento/galeria/bernardino-sahagun-codices-matritenses/ fo_06.

Thouvenot, Marc y Javier Manríquez. 2014. Diccionario Náhuatl-Español. Basado en los diccionarios de Alonso de Molina con el náhuatl normalizado y el español modernizado. México: Instituto de Investigaciones Históricas, UNAM, Fideicomiso Felipe Teixidor y Monserrat Alfau de Teixidor. http://www.historicas.unam.mx/publicaciones/publicadigital/libros/diccionario/nahuatl.html

Vauzelle, Loïc. 2017. "Los dioses mexicas y los elementos naturales en sus atuendos: unos materiales polisémicos". Trace 71: 76-110. https://doi.org/10.22134/trace.71.2017.54. 